\title{
Percutaneous venting gastrostomy/gastrojejunostomy for malignant bowel obstruction: a qualitative study
}

Singh Curry, Rebecca; Evans, Elizabeth; Raftery, Anne-Marie; Hiscock, Julia; Poolman, Marlise

\section{BMJ Supportive and Palliative Care}

\section{DOI:}

10.1136/bmjspcare-2019-001866

Published: 03/12/2019

Peer reviewed version

Cyswllt i'r cyhoeddiad / Link to publication

Dyfyniad o'r fersiwn a gyhoeddwyd / Citation for published version (APA):

Singh Curry, R., Evans, E., Raftery, A-M., Hiscock, J., \& Poolman, M. (2019). Percutaneous venting gastrostomy/gastrojejunostomy for malignant bowel obstruction: a qualitative study. BMJ Supportive and Palliative Care, 9(4), 381-388. https://doi.org/10.1136/bmjspcare-2019-001866

\footnotetext{
Hawliau Cyffredinol / General rights

Copyright and moral rights for the publications made accessible in the public portal are retained by the authors and/or other copyright owners and it is a condition of accessing publications that users recognise and abide by the legal requirements associated with these rights.

- Users may download and print one copy of any publication from the public portal for the purpose of private study or research.

- You may not further distribute the material or use it for any profit-making activity or commercial gain

- You may freely distribute the URL identifying the publication in the public portal ?
}

Take down policy

If you believe that this document breaches copyright please contact us providing details, and we will remove access to the work immediately and investigate your claim. 
Percutaneous Venting Gastrostomy/Gastrojejunostomy in the Management of Malignant

Bowel Obstruction: A Qualitative Study Exploring Patients' Experiences

\section{Dr Rebecca Singh Curry}

Specialist Palliative Care Team, Willow House, Stockport NHS Foundation Trust, Stepping Hill Hospital, Stockport. SK2 7JE. UK.

\section{beckisingh@doctors.org.uk}

Telephone: 01614194215

Fax: 01614194051

\section{Dr Elizabeth Evans}

Specialist Palliative Care Team, Bangor University, North Wales Centre for Primary Care Research, Gwenfro Unit 5. Wrexham Technology Park, Wrexham. LL13 7YP. UK.

\section{Ms Anne-Marie Raftery}

The Supportive Care Team, The Christie NHS Foundation Trust, Wilmslow Road, Manchester. M20 4BX. UK.

\section{Dr Julia Hiscock}

Specialist Palliative Care Team, Bangor University, North Wales Centre for Primary Care Research, Gwenfro Units 4-8. Wrexham Technology Park, Wrexham. LL13 7YP. UK.

\section{Dr Marlise Poolman}

Specialist Palliative Care Team, Bangor University, North Wales Centre for Primary Care Research, Gwenfro Units 5-7. Wrexham Technology Park, Wrexham. LL13 7YP. UK.

Keywords/phrases: percutaneous venting gastrostomy, malignant bowel obstruction, patient experience, qualitative.

Word Count: 3550 (excluding quotes, tables and references) 


\section{Abstract \\ Objective}

Malignant Bowel Obstruction (MBO) is a complication of advanced malignancy and is associated with a short prognosis. MBO can infrequently be reversed by surgery or stenting. The focus of treatment is usually symptomatic management, of which percutaneous venting gastrostomy/gastrojejunostomy (PVG) is one consideration. There is little data considering the impact of PVG on quality of life; we therefore aimed to explore this.

\section{Methods}

We identified patients with PVG inserted for MBO and those who consented to participate were interviewed. The interviews were audio-recorded, transcribed and analysed using Framework. Alongside patient interviews, a data collection tool was designed and utilised to record patient demographics and medical information, enabling us to contextualise individual patients' experiences.

\section{$\underline{\text { Results }}$}

11 patients were interviewed and 10 patients' data was analysed (1 patient withdrew). No patients regretted having a PVG and many benefitted symptomatically and psychosocially. Challenges encountered included practical issues, pain and PVG tube complications.

\section{Conclusions}

The analysis provided a detailed insight into the impact of PVG insertion and demonstrated that each patients' experience is shaped by a complex interplay of individual factors, thereby highlighting the need to improve referral criteria and individualise patient selection. Other service improvements include enhancing information provision for patients and training for Healthcare Professionals', thus aiming to mitigate the challenges experienced. Our study is the first in-depth exploration of patients' experiences of PVG at a tertiary cancer centre. Ensuring that the insights from this study are fed back to guide future service provision is critical in enhancing future patient experiences. 


\section{Introduction}

Malignant Bowel Obstruction (MBO) affects around 3-15\% of patients with advanced cancer globally. The incidence is higher in certain cancers; up to $50 \%$ in ovarian carcinoma and up to $28 \%$ in colorectal carcinoma. MBO can be mechanical or functional, but is often both. Life expectancy is generally short for patients who develop this complication, with a median survival of 10 weeks [1-3].

Management options for $\mathrm{MBO}$ can be divided into reversal of the obstruction or symptomatic control. Reversal of the obstruction encompasses surgery or endoluminal stenting. In selected patients, with a single site mechanical obstruction, surgery is likely to be beneficial [4-5], yet this excludes the majority of patients. 30-day surgical mortality can reach up to $40 \%$, with complication rates up to $90 \%$ [4]. Endoluminal stenting has a role in selected patients; a gastroduodenal stent may be feasible for a single obstruction at the gastric outlet or proximal small bowel, and a colonic stent for a focal colo-rectal obstruction, providing there is a sufficient margin from the anus [5]. If reversal of the obstruction is not feasible patients are managed by optimising their symptoms.

Symptom control can be subdivided into medical interventions and insertion of a percutaneous venting gastrostomy/gastrojejunostomy (PVG). Medical interventions may include keeping the patient nil by mouth (NBM), decompressing the stomach and bowel with a nasogastric tube (NGT) and an intravenous infusion (IVI); (the 'drip and suck' method), as well as parenteral medications for symptom control. Generally, an NGT is only justified short-term due to the complications of prolonged use [6], although in a minority of cases they may remain in situ for weeks/months.

In the tertiary cancer centre where we conducted the study the interventional radiologists (IR) perceive a role for PVG when parenteral medications achieve suboptimal symptom control, and ideally following a successful trial of NGT decompression [7]. An IR assesses patients referred for PVG and suitable patients wanting to proceed sign a written consent form. A patient information pack is available, containing a summary of general pre-PVG information (including 'what is a venting gastrostomy tube', 'why do I need it', 'how can I control my symptoms' and dietary advice), followed by detailed post-PVG care information. On discharge a PVG specific discharge letter is completed alongside the standard hospital discharge letter.

Improving our understanding of the management options is critical for those treating these patients. Published evidence on PVG has largely focused on feasibility, success rates, symptomatic relief, complications and survival. Research has demonstrated symptomatic relief rates of over 90\% [8-11] and restoration of some diet in over $90 \%$ of cases [8-10]. Patients' experiences of PVG insertion and the impact on their quality of life (QoL) remains unclear. These factors need to be examined to enable clinicians and patients to make more informed decisions regarding MBO management and patient selection for PVG. 
This study aimed to explore individual patient experiences of PVG alongside information regarding their treatment journey. We aim to feedback to the PVG service providers and guide service development to enable more informed decision making, thereby enhancing patient experience.

\section{Methods}

This study was undertaken as part of a wider study with the ultimate aim to devise a PVG registry within the tertiary hospital. Prior to this the team felt it would be beneficial to further explore patient experiences with PVG. Our proposal was submitted to the hospital's Research and Development Department, who decided that this would best be defined as a service evaluation project (reference number CE15/1486).

Qualitative interviews were used to facilitate an in-depth exploration of patient experiences of PVG. The interviews enabled patients to verbalise their first-hand experiences and to guide the areas of discussion relevant to their particular 'journey'. Pertinent information from the patient's medical notes was collected to enable contextualisation of responses. Both sets of results were blended together providing a more informative analysis.

Patients had to fulfil all of the inclusion criteria in order to be eligible to participate:

- Adults ( $\geq 18$ years of age), and

- Diagnosis of MBO, and

- Had already undergone (retrospective) or were due to and subsequently did undergo (prospective) PVG.

\section{Recruitment}

The study had a six-month recruitment window (January 2016 to July 2016), which was predetermined to coincide with the study block of the interviewers. We approached those that had a PVG inserted previously and were still alive (retrospective), alongside patients that had a PVG inserted during the study period (prospective). This maximised our sample size and gathered longer and shorter-term experiences. Patients were screened against the inclusion criteria and eligible patients were approached by an interviewer who outlined the study. This was done via telephone, when they attended the interventional radiology department for review, or during their inpatient admission.

Demographic and medical information was gathered using a pre-generated collection tool (appendix A) for screening and contextual background information.

\section{Consent}

Following a discussion with an interviewer, patients interested in participating were provided with a study information leaflet and were given as much time as required to consider this. Those that decided to participate then provided written consent. Patient 3 
wished to participate in the study, however due to fatigue he asked his wife to speak on his behalf, whilst he was also present. In this case his wife signed the consent form.

\section{Interviews}

The semi-structured interview guide (appendix B) was developed by the wider multidisciplinary project team; including IRs, palliative care clinicians and a qualitative researcher. It was devised to address the study objectives and was finalised following team discussions after each iteration. Interviews were conducted by two members of the study team (junior doctors), and patients were informed that they were not acting in their healthcare professional capacity. Both received training and supervision from an experienced qualitative researcher. The duration of the interviews was patient led, typically lasting around 60 minutes.

We aimed to interview patients identified prospectively at least one-week post-PVG insertion. All interviews were audio-recorded and transcribed verbatim. Interviews were face-to-face and occurred in hospital wards or the patients' homes. If the initial interview was conducted prior to one-week post-PVG insertion we aimed to re-interview the patient. Follow-up interviews, where applicable, were conducted by telephone, audio-recorded and transcribed verbatim.

\section{Analysis}

The interview data was analysed using Framework [12], a systematic, five-stage matrixbased system that facilitates analysis both by theme and by case [12-16]. While less suitable for in-depth heavily theoretical research, the Framework method is recognised for its suitability for applied studies such as this and is valued for its transparency and clarity [17]. The five stages included familiarisation with the data from the interviews, inductive development of a framework, generation of an index for themes and subthemes (developed by interrogating data categories through comparison between and within cases), data synthesis and interpretation. Multidisciplinary team (MDT) workshops were held for discussion of emerging themes and interpretations. These were led by a senior qualitative researcher with a social science background.

The demographic and medical information gathered using our data collection tool (appendix A) was combined with this data to help contextualise and interrogate the data as part of our analysis. 


\section{$\underline{\text { Results }}$}

We will first report patient demographics and pre-PVG MBO management. Then we will discuss the themes which emerged from the interviews under the following headings: overall views, positive experiences and challenges encountered with PVG. Finally, we will offer suggestions for future service improvement.

Demographics

$11 / 15$ (73\%) eligible patients were recruited to our study. Of the 4 (27\%) patients who were not recruited; $2 / 4$ (50\%) were uncontactable, $1 / 4$ (25\%) declined and 1/4 (25\%) was judged inappropriate to approach as the patient was felt to be in the last hours of life. 12 interviews were conducted; 11 face-to-face initial interviews and 1 telephone re-interview. $9 / 11(82 \%)$ of the face-to-face interviews were conducted in hospital and 2/11 (18\%) were conducted in patients' homes. $1 / 11$ patients (Patient 5) withdrew from the study, leaving 10 patients' data for analysis (Table 1 ).

The median survival post-PVG was 92 days, with a range of 10 days to 1,837 days. 


\section{TABLE 1: PATIENT CHARACTERISTICS}

\begin{tabular}{|c|c|c|c|c|c|c|c|}
\hline Patient & Age (Years) & Sex & Cancer Diagnosis & Episode of MBO & Referrer & PN Pre-PVG & Recruited \\
\hline 1 & 36 & Female & Ovarian & 3 & Supportive Care Team & Yes & Prospectively \\
\hline 2 & 72 & Female & Ovarian & 4 & Oncologist & Yes & Retrospectively \\
\hline 3 & 79 & Male & Colorectal & 1 & Oncologist & No: inappropriate & Prospectively \\
\hline 4 & 73 & Female & Endometrial & 3 & Oncologist & Yes & Retrospectively \\
\hline 6 & 67 & Female & Ovarian & 1 & Oncologist & No: patient chose BSC & Prospectively \\
\hline 7 & 77 & Female & Neuroendocrine: small bowel & 3 & Oncologist & Yes & Retrospectively \\
\hline 8 & 60 & Female & Peritoneal & 1 & Oncologist & No: patient chose BSC & Prospectively \\
\hline 9 & 72 & Female & Ovarian & 1 & Oncologist & Yes & Prospectively \\
\hline 10 & 59 & Female & Appendiceal & 1 & Surgeon & Yes & Prospectively \\
\hline 11 & 56 & Female & Appendiceal & 4 & External: IFU Team & Yes & Prospectively \\
\hline
\end{tabular}

BSC = Best Supportive Care; IFU = Intestinal Failure Unit; $\mathrm{MBO}=$ Malignant Bowel Obstruction; PN = Parenteral Nutrition; PVG = Percutaneous Venting Gastrostomy/Gastrojejunostomy. 


\section{Pre-PVG MBO management}

Patients experienced a range of management options during their $\mathrm{MBO}$ course (Table 2). Attempts were made to reverse previous episodes of $\mathrm{MBO}$; with 2/10 (20\%) patients undergoing surgery for at least one episode of their MBO.

With regards to medical interventions, all of the patients had experienced at least one NGT insertion during an episode of MBO, with $9 / 10$ (90\%) patients having an NGT inserted during their current episode. The patient with no NGT in situ during their current episode declined because she found it unbearable. $7 / 10$ (70\%) patients had a syringe pump during their current episode of $\mathrm{MBO}$. A variety of regular and as required medications were prescribed, and varying doses of the same drug were prescribed. The antiemetic drug doses in patients' 2, 8 and 9 syringe pumps are noted to be particularly low. Additionally, four patients $(2,4,6$ and 9$)$ syringe pumps contained a single antiemetic.

9/10 (90\%) of patients received the written information pack entitled 'Venting Gastrostomy Information Pack.' 


\begin{tabular}{|c|c|c|c|c|c|c|c|c|c|}
\hline \multirow[b]{2}{*}{$\begin{array}{l}\text { Patient } \\
\end{array}$} & \multirow[b]{2}{*}{ Previous Oncological Treatment Prior to Developing MBO } & \multicolumn{2}{|c|}{ Management of Previous Episodes of MBO } & \multicolumn{4}{|l|}{ Management of Current Episode of MBO } & \multirow[b]{2}{*}{$\begin{array}{l}\text { PVG insertion } \\
\text { to Interview } \\
\text { (Days) }\end{array}$} & \multirow[b]{2}{*}{$\begin{array}{l}\text { Post-PVC } \\
\text { Survival } \\
\text { (Days) }\end{array}$} \\
\hline & & Medical & Surgical/Stent? & CsCl? & Medical/Surgical/Stent? & NGT? & Other & & \\
\hline 1 & $\begin{array}{l}\text { TAH, BSO \& omentectomy } \\
6 \text { lines of chemotherapy }\end{array}$ & $\begin{array}{l}1^{\text {st: }} \text { Conservative } \\
2^{\text {nd }}: \text { Conservative }\end{array}$ & No & $\begin{array}{l}\text { Yes: } \\
\text { Pump 1: Octreotide 600micrograms/24hrs } \\
\text { Pump 2: Levomepromazine } 18.75 \mathrm{mg} / 24 \mathrm{hrs}, \\
\text { Diamorphine } 100 \mathrm{mg} / 24 \mathrm{hrs} \& \\
\text { Hyoscine Butylbromide } 80 \mathrm{mg} / 24 \mathrm{hrs}\end{array}$ & $\begin{array}{l}\text { 3rd: No, but IR raised the } \\
\text { possibility that a stent may be } \\
\text { required in addition to a PVG due } \\
\text { to GOO as well as distal SBO }\end{array}$ & Yes & $\begin{array}{l}\text { Granisetron Patch } 3.1 \mathrm{mg} / 24 \mathrm{hrs} \\
\text { every } 5 \text { days }\end{array}$ & $\begin{array}{l}1^{\text {st }}: 2 \\
2^{\text {nd }}: 43\end{array}$ & 98 \\
\hline 2 & $\begin{array}{l}\text { Laparotomy, BSO \& omentectomy } \\
1 \text { line of chemotherapy }\end{array}$ & $\begin{array}{l}1^{\text {st: }} \text { Switched to } 2^{\text {nd }} \text { line } \\
\text { chemotherapy } \\
2^{\text {nd: }} \text { Switched to } 3^{\text {rd }} \text { line } \\
\text { chemotherapy } \\
3^{\text {rd }}: \text { Switched to } 4^{\text {th }} \text { line } \\
\text { chemotherapy }\end{array}$ & No & Yes: Octreotide 200micrograms/24hrs & $\begin{array}{l}\text { 4th: Trialled 5th line } \\
\text { chemotherapy }\end{array}$ & Yes & $\begin{array}{l}\text { PRNs: Hyoscine Butylbromide, } \\
\text { Cyclizine \& Levomepromazine }\end{array}$ & 27 & 59 \\
\hline 3 & $\begin{array}{l}\text { Defunctioning stoma } \\
\text { Radical cystoprostatectomy, sigmoid colectomy \& urostomy } \\
\text { Partial hepatectomy } \\
\text { Palliative radiotherapy } \\
3 \text { lines of chemotherapy }\end{array}$ & N/A & $\mathrm{N} / \mathrm{A}$ & No & & Yes & $\begin{array}{l}\text { PRNs: Cyclizine, Ondansetron \& } \\
\text { Paracetamol }\end{array}$ & 5 & 10 \\
\hline 4 & $\begin{array}{l}\text { TAH \& BSO } \\
\text { EBRT } \\
\text { Total pelvic exenteration with mid-colostomy \& ileal conduit } \\
\text { formation } \\
2 \text { lines of chemotherapy }\end{array}$ & $\begin{array}{l}1^{\text {st: }} \text { Conservative } \\
2^{\text {nd }}: \text { Conservative }\end{array}$ & No & $\begin{array}{l}\text { Yes: Cyclizine } 150 \mathrm{mg} / 24 \mathrm{hrs} \& \\
\text { Oxycodone } 30 \mathrm{mg} / 24 \mathrm{hrs}\end{array}$ & & Yes & & 70 & 95 \\
\hline 6 & 3 lines of chemotherapy & N/A & $\mathrm{N} / \mathrm{A}$ & Yes: Cyclizine $150 \mathrm{mg} / 24 \mathrm{hrs}$ & & Yes & & $\begin{array}{c}1^{\text {st }: 4} \\
2^{\text {nd: }}: \text { cancelled } \\
\text { (died) }\end{array}$ & 27 \\
\hline 7 & None & & $\begin{array}{l}\text { Yes: } 1^{\text {st: }} \text { initial presentation } \\
\text { of cancer was with MBO: } \\
\text { laparotomy and small bowel } \\
\text { resection } \\
2^{\text {nd: }}: \text { right hemicolectomy }\end{array}$ & No & & Yes & & 1095 & 1837 \\
\hline 8 & $\begin{array}{l}\text { BSO \& omentectomy } \\
3 \text { lines of chemotherapy }\end{array}$ & N/A & $\mathrm{N} / \mathrm{A}$ & $\begin{array}{l}\text { Yes: Haloperidol } 1.25 \mathrm{mg} / 24 \mathrm{hrs}, \\
\text { Hyoscine Butylbromide } 20 \mathrm{mg} / 24 \mathrm{hrs} \& \\
\text { Morphine } 10 \mathrm{mg} / 24 \mathrm{hrs}\end{array}$ & & Yes & & 7 & 13 \\
\hline 9 & $\begin{array}{l}\text { TAH, BSO \& omentectomy } \\
2 \text { lines of chemotherapy }\end{array}$ & N/A & $\mathrm{N} / \mathrm{A}$ & Yes: Octreotide 300micrograms/24hrs & $\begin{array}{l}\text { 1st: Trialled 2nd line } \\
\text { chemotherapy }\end{array}$ & Yes & $\begin{array}{l}\text { PRNs: Cyclizine \& } \\
\text { Levomepromazine }\end{array}$ & 6 & 91 \\
\hline 10 & $\begin{array}{l}\text { Right hemicolectomy and small bowel resection } \\
1 \text { line of chemotherapy }\end{array}$ & N/A & N/A & No & & Yes & $\begin{array}{l}\text { PRNs: Paracetamol, Oxycodone, } \\
\text { Cyclizine \& Ondansetron }\end{array}$ & 8 & 152 \\
\hline 11 & $\begin{array}{l}\text { Tumour resection } \\
\text { Debulking surgery } \\
3 \text { lines of chemotherapy }\end{array}$ & $\begin{array}{l}1^{\text {st: }} \text { : witched to } 4^{\text {th }} \text { line } \\
\text { chemotherapy } \\
3^{\text {td: }: \text { Conservative }}\end{array}$ & $\begin{array}{l}\text { Yes: } 2^{\text {nd }} \text { : resection \& } \\
\text { ileostomy formation }\end{array}$ & $\begin{array}{l}\text { Yes: Levomepromazine } 25 \mathrm{mg} / 24 \mathrm{hrs} \& \\
\text { Cyclizine } 150 \mathrm{mg} / 24 \mathrm{hrs}\end{array}$ & & No* & $\begin{array}{l}\text { PRNs: Oxycodone, } \\
\text { Prochlorperazine \& Paracetamol }\end{array}$ & 8 & 93 \\
\hline
\end{tabular}




\section{Patients' overall PVG experience}

All patients stated that they did not regret having a PVG inserted and all patients reported that they would recommend another patient in a similar position to consider PVG insertion. We explored the reasoning behind this.

One reason was survival, with several patients being glad they had undergone PVG due to their perception that it had increased their survival. Some felt there was no alternative to PVG, with others believing that PVG insertion was optimal because it came recommended by a medical professional.

"Certainly yes, I mean what's the alternative...you just have to go with what the doctors recommend I think."

(Patient 2, female, age 72, 4 weeks post-PVG)

\section{Patients' positive PVG experiences}

Patients discussed two main positive impacts of PVG on their life; amelioration of symptoms and enabling their NGTs to be removed [for all but 1/10 (10\%); Patient 1].

All reported that their nausea and vomiting either reduced or subsided completely post-PVG insertion. Other improvements included reductions in pain and abdominal distention.

"Well they explained that it would be helpful for the sickness...stopping the sickness, which it did. I was so grateful for that because it was just projectile all the time."

(Patient 7, female, age 77, 3 years post-PVG)

Removal of their NGTs was seen as a benefit post-PVG insertion; improving their comfort, body image and dignity. Body image was greatly improved following NGT removal for many who described feeling self-conscious due to the visibility of their NGT. Patient 3 and his Spouse referred to his NGT as a 'trunk'. In contrast to their NGT, many patients were pleased that their PVG could be hidden, resulting in increased self-assurance and facilitating them going out in public and socialising. 
"I hated that up my nose because it was so uncomfortable. It hurt me...it was horrible and uncomfortable in my throat, but this (referring to her PVG tube) isn't uncomfortable."

(Patient 2, female, age 72, 4 weeks post-PVG)

\section{Challenges with PVG}

Despite the positive experiences, there were some challenges raised by patients regarding their PVG. These include practical issues, psychosocial issues, pain and PVG tube complications.

One practical difficulty related to tube anatomy; patients were required to remove the stopper at the end of the tube to drain stomach contents. Some struggled with this, especially those with reduced manual dexterity and those with decreased functional status. Others felt their PVG impeded their mobility; particularly patients with multiple devices/attachments; such as Parenteral Nutrition (PN), stomas and syringe pumps.

(are you able to walk up and down the stairs?)

"...not when carrying my bags (referring to her PVG, PN and syringe pump), but X (partner) carries those either behind or in front of me."

(Patient 9, female, age 72, 1-week post-PVG, at home)

The PVG affected social confidence. One patient felt conscious of an odour perceived to be coming from her PVG, described as 'sewage'. This caused anxiety due to her concern that others could smell this.

"You can smell it though, even if it's not leaking. I feel like...it smells like sewage, it's not faecal, it's worse than that, it's a sewage smell and I feel like I can smell it all the time and anyone who is anywhere near me can smell it. It is making me quite paranoid, I am constantly asking my husband if he can smell it...I don't get embarrassed too easily, but I do find that quite difficult to deal with."

(Patient 1, female, age 36, 6 weeks post-PVG)

Some felt the pain post-procedure was more severe or lasted longer than anticipated. Some patients developed an infection and were treated with antibiotics. Furthermore, some patients experienced leakage of gastric contents due to their tube bypassing, causing discomfort. For one patient, the volume resulted in their bedsheets being changed several times per day. 
Despite interventions to minimise this leakage, this patient's skin became necrotic.

"My husband has been in a lot of discomfort, it has been leaking all the time, he's being changed numerous times a day, the beds have to be changed and now his skin is all sore."

(Patient 3, male, age 79, 1-week post-PVG)

Other complications included tubes dislodging, with one patient's tube falling out multiple times. All tubes were initially confirmed as correctly sited, yet several tubes were subsequently found to be displaced. Imaging revealed that two patients' tubes were in their oesophagus.

\section{$\underline{\text { Identified areas for service improvement }}$}

All of the patients discussed ways in which they felt their experience of PVG could be enhanced; largely divided into the provision of patient information and HCPs' education and training.

Information provision encompassed; PVG specific information, the timing, quantity and consistency of information, as well as follow-up information.

For many of the patients, a PVG was initially raised by their treating team (as seen in Table 1). During this initial discussion many felt they would have benefitted from more information; why a PVG was being considered, what they could expect from a PVG and alternative options. Many felt they made the decision to proceed with a PVG without this, with the first in-depth conversation being during the written consent process with an IR. Some felt reassured with this information provided by the individual that was to perform the procedure and felt this instilled trust in that clinician. Others felt that receiving detailed information at this point was too late.

"... when I got down to radiology, $\operatorname{Dr} X$ (Consultant IR) came and explained it all to me and I was even more anxious then because I sort of then understood what was happening..."

(Patient 10, female, age 59, 1-week post-PVG, not given any written information pre-PVG)

The hospital provided a written resource on PVG which was given to patients at different times; some received this before their procedure, whereas others received it after PVG insertion. As it is a detailed document the patients felt it 
should be provided a reasonable amount of time beforehand to enable digestion of the information. One suggested improvement was to include patient stories containing positive and negative experiences.

Overlapping somewhat with information provision is HCPs' education and training. This includes HCPs ensuring patients are adequately informed prior to PVG insertion to facilitate realistic patient expectations, in addition to staff being competent and confident in post-PVG care, both in the hospital and community.

Some patients had unrealistic expectations, such as; their PVG would completely resolve their symptoms, guarantee resumption of their usual diet and/or prolong their life expectancy. One patient was given conflicting information regarding the care of her PVG. One patient did not feel confident in the way that the HCPs' cared for her PVG tube and some felt that they were not supported by HCPs to facilitate their autonomy in caring for their PVG.

(Referring to ward nurses):

“...one nurse who was giving it a clean said, you don't rotate this one...that other nurse, she said something about l'll rotate it and I said oh well I've been told not to rotate mine."

(Patient 6, female, age 67, 1-week post-PVG)

\section{Discussion}

This study explored patients' experiences of PVG in the management of MBO. This was achieved through interviews with patients post PVG insertion alongside data collection regarding their patient journey. All patients felt PVG had enhanced their quality of life; symptomatically, psychosocially and through the restoration of some dietary intake. Alongside this, all patients experienced a PVG related challenge/challenges, although the nature and degree of these varied. Ultimately, all patients were pleased they had gone ahead with the procedure. Through the enhancement of information provision and HCPs' education and training, the challenges faced by patients could be mitigated somewhat, whilst also acknowledging that it is not always possible to predict or prevent side effects and/or complications of a procedure.

Whilst this study was performed primarily for service evaluation, it is important in contributing to the existing published literature, as it is the first 
in-depth exploration of patients' experiences of PVG using qualitative methods. Existing literature demonstrates the role of PVG in MBO in terms of technical success rates, complications, effectiveness of symptomatic control and survival. This study can be used to improve awareness of PVG and the understanding of how PVG insertion can affect patients. In addition, the use of mixed methods (qualitative interviews combined with reviews of patients' medical notes) enabled a greater depth to the data analysis.

Patient selection for PVG is an important area to consider. The results suggest that the medical management of MBO was not always fully optimised pre-PVG. Three patients did not have a continuous subcutaneous infusion $(\mathrm{CSCl})$ of medication during their current episode of MBO. This includes Patient 3 whom developed skin necrosis, secondary to his tube bypassing. Ensuring patients have undergone a trial of optimal tolerated medical management prior to PVG consideration would help to prevent patients unnecessarily undergoing PVG insertion. Defining what this should include is challenging, especially regarding choices of medication, drug combinations and doses. However, amongst the patients with a $\mathrm{CSCl}$ in situ many of the doses were lower than would usually be tried by the Hospital's Supportive Care/Specialist Palliative Care Team.

Another factor to consider in patient selection is prognosis. Patient 3 had the shortest post-PVG survival at 10 days. Estimating prognosis can be difficult and inaccurate, but with hindsight at least, this case highlights the need for an appropriate clinician to attempt to estimate prognosis when referring patients for a PVG.

In terms of patient selection, this study raises the possibility of creating a standardised referral pathway. Standardised referral pathways are utilised in many areas of clinical medicine, however establishing such a pathway in this subgroup of patients is more challenging. Criteria may include: where optimally tolerated doses of medications via a parenteral route have failed to adequately control symptoms and where a trial of an NGT has been symptomatically beneficial. Ensuring that the patient has been reviewed by the Hospital's Supportive Care/Specialist Palliative Care Team and/or had their case discussed at an appropriate MDT meeting will increase the likelihood of satisfying the suggested criteria.

Some of the reported challenges could have been pre-empted or were known potential side effects and/or complications of the procedure, such as, patients with reduced manual dexterity struggling with tube fastenings and an inverse 
relationship between the number of attachments and the effect on mobility. Known possible side effects and/or complications include infections and bypassing tubes causing a leakage of gastric contents. This reinforces a recommendation for individual patient assessment pre-PVG, including an explanation of possible side effects and complications, supported by written information. This may help patients to make a more informed decision and could reduce some of the challenges, due to patients having more realistic expectations.

Furthermore, complications could be reduced and perhaps avoided through training combined with a competency assessment, in the aftercare of PVGs for nursing staff. One example of this is the frequency of tube displacement. Patient 6's comment implies that some nurses might be rotating PVG tubes. This may highlight an area of training which needs to be addressed; to ensure that staff are aware of the differences between a Percutaneous Endoscopic Gastrostomy (PEG) for Clinically Assisted Nutrition (CAN) and PVG.

Emphasising that despite the equipment being very similar, their management is different.

There is a need to improve the provision of patient information, and this could be implemented in several ways:

- Ensuring that all patients are offered written information.

- Agreeing a time point, pre-PVG for this information to be provided, facilitating adequate reading and processing time, and an opportunity to ask questions.

- Reformatting the written information; separating pre-PVG and postPVG; supporting a more flexible and individualised approach to the provision of information.

- Guaranteeing that information is easily accessible to any referring team (via the hospital's intranet); potentially informing, empowering and improving both initial pre-PVG as well as post-PVG discussions.

The above should create a more robust process of informed consent and more realistic patient expectations.

The results demonstrate a complex interplay of individual patient factors which shaped these patients' experiences. They highlight a need for the development of PVG referral criteria to improve patient selection. In addition, 
services need to address patient information provision, skills and competencies of HCPs and PVG aftercare.

It is important to acknowledge limitations of the study. With regards to study design, the study period was predetermined to coincide with the study periods of the interviewers. Despite this, the interviewer felt that the saturation point had been reached in this period, as no new themes emerged during the last two interviews. There was variation in the time between PVG insertion and interview; our aim to interview patients one-week post PVG insertion proved challenging. This was due to interviewer availability and patient factors. Interviewing patients only a few days post-PVG meant some were unable to provide fully informed views; where this was the case the interviewer attempted to organise a re-interview (one of the two re-interviews was cancelled as the patient died). There was a risk of bias in that the interviewers were involved in the care of some of the patients; we aimed to minimise this by reassuring patients that the doctor was not acting in their HCP role, however this does not completely eradicate the risk of bias. In order to counteract the bias associated with two different interviewers, both received training and supervision by a senior qualitative researcher. With regards to the patient sample, it included only one male patient. Although gender was not considered a prime purposive sampling criterion, it may be felt that the patient group is not truly representative of the general population.

There are further factors to be explored in future studies, such as a potential correlation between the use of parenteral nutrition and survival. Considering the health economics of PVG insertion would also be beneficial, with regards to the cost of the insertion procedure compared to a possible reduction in acute admission costs. Furthermore, it would be beneficial to establish if PVG enables greater patient autonomy in facilitating factors such as discharge to their preferred place of care. Unfortunately, these considerations were beyond the remit of the data collected in this study, but would be useful in determining which patients would benefit from PVG in MBO.

Existing literature demonstrates that PVG is an accepted procedure for the symptomatic management of MBO. This study is the first to focus on patients' experiences of their PVG using qualitative methods, whilst contextualising this information with their individual MBO journeys. We strongly believe that despite the limitations of this study, the patient voice conveyed in the results 
can enhance future care delivery if the suggestions made are implemented as per standard quality improvement methodologies.

\section{Table Legends}

\section{TABLE 1: PATIENT CHARACTERISTICS}

\section{TABLE 2: SUMMARY OF PATIENTS' JOURNEYS}

\section{Contributorship}

$\mathrm{JH}, \mathrm{MP}$ and RSC were responsible for conception, design and the whole protocol and contributed to all components of the study. JH and MP oversaw the study. All the authors were responsible for the organisation and conduct of the study. RSC was responsible for acquisition of study data. EE was responsible for data analysis and all authors (except AMR) for interpretation of study data. EE and RSC drafted the manuscript. All authors critiqued the output. All authors read and approved the final manuscript.

All authors would like to thank the patients who participated in this study, the interventional radiology department, nutrition nurse and supportive care team at The Christie NHS Foundation Trust.

\section{Declarations}

Our study was approved as a service evaluation project by the research and development department at The Christie Hospital (a tertiary cancer centre); Reference number CE15/1486.

This project did not receive external funding and was undertaken as the academic project of trainee doctors (RSC and EE). They are joint first authors for this manuscript.

Competing Interest: None declared.

The Corresponding Author has the right to grant on behalf of all authors and does grant on behalf of all authors, an exclusive licence (or non-exclusive for government employees) on a worldwide basis to the BMJ Publishing Group Ltd to permit this article (if accepted) to be published in BMJ Supportive and Palliative Care and any other BMJPGL products and sublicences such use and exploit all subsidiary rights, as set out in our licence (http://group.bmj.com/products/journals/instructions-for-authors/licence- 
forms). 


\section{Appendix A}

\section{Concurrent Audit Data}

Patient identifying number (NHS/Unit no):

Pre-procedure

- Age years

- Gender

Male $\square$

Female $\square$

- Postcode

- Primary diagnosis

Bowel cancer $\square$ Ovarian cancer $\square$ Other:

- Date of diagnosis

- MBO history

- Date of MBO

- Complete or sub-acute

- Medications

- Involvement of palliative care team $(\mathrm{Y} / \mathrm{N})$

- Expected date of death/date of death

PVG

- Who referred the patient for PVG?

Palliative Care $\square$ Dietician $\square$ Oncologist $\square$ Surgeon $\square$ Other:

- Date of PVG

- Name of practitioner that inserted PVG

- Gastro or gastrojejunostomy Gastrostomy $\square \quad$ Gastrojejunostomy $\square$

- Eastern Co-operative Oncology Group (ECOG) Performance Status Score o Pre-procedure:

o Post-procedure: 


\section{Appendix B}

Semi-structured interview guide

\section{Initial symptoms}

1.1 Vomiting

1.2 Nausea

1.3 Pain

1.4 Bloating

1.5 Bowels

1.6 Eating and drinking

2 NGT

2.1 Reason for insertion

2.2 Experience of insertion procedure

2.3 Benefits provided by NGT

2.4 Negative impact of NGT

3 PVG: Pre-procedure

3.1 Reason for insertion

3.2 Patient expectations of PVG

3.3 Information provided

4 PVG: Procedure

4.1 Sedation and experience

4.2 Staff

4.3 Recovery

5 PVG: Post-procedure

5.1 Benefits

5.2 Complications/side-effects

5.3 Practicalities for the patient 
5.4 Ongoing care of the PVG

6 Overall experience of PVG

6.1 Did a PVG meet their expectations?

6.2 Does the patient regret the procedure?

6.3 Would the patient recommend the procedure to another patient? 


\section{$\underline{\text { References }}$}

1. Tuca A, Guell E, Martinez-Losada E, Codorniu N. Malignant bowel obstruction in advanced cancer patients: epidemiology, management, and factors influencing spontaneous resolution. Cancer Manag Res. 2012; 4: 159169.

2. Feuer DDJ, Broadley KE. Surgery for the resolution of symptoms in malignant bowel obstruction in advanced gynaecological and gastrointestinal cancer. Cochrane Database of Systematic Reviews 2000, Issue 3. Art. No.: CD002764. DOI: 10.1002/14651858.CD002764.

3. Anthony T, Baron T, Mercadante S, et al. Report of the clinical protocol committee: development of randomized trials for malignant bowel obstruction. J Pain Symptom Manage. 2007;34: S49-S59.

4. Ripamonti C, Twycross R, Baines $M$, et al. Clinical-practice recommendations for the management of bowel obstruction in patients with end-stage cancer. Support Care Cancer. 2001; 9:223-233.

5. Ripamonti $\mathrm{Cl}$, Easson AM, Gerdes $\mathrm{H}$. Management of malignant bowel obstruction. Eur J Cancer. 2008; 44:1105-1115.

6. Ripamonti C, Mercadante S. Pathophysiology and management of malignant bowel obstruction. In: Hanks G, Cherny NI, Christakis NA et al (ed.), Oxford textbook of palliative medicine. 4th ed. Oxford: Oxford University Press, 2010, 850-863.

7. Dolan EA. Malignant bowel obstruction: a review of current treatment strategies. Am J Hosp Palliat Care. 2011; 28:576-582.

8. Brooksbank MA, Game PA, Ashby MA. Palliative venting gastrostomy in malignant intestinal obstruction. Palliat Med. 2002; 16:520-526.

9. Pothuri B, Montemarano M, Gerardi M, et al. Percutaneous endoscopic gastrostomy tube placement in patients with malignant bowel obstruction due to ovarian carcinoma. Gynecologic Oncology. 2005; 96:330-334.

10. Cannizzaro R, Bortoluzzi F, Valentini M, et al. Percutaneous endoscopic gastrostomy as a decompressive technique in bowel obstruction due to abdominal carcinomatosis. Endoscopy. 1995; 27(4):317-320. 
11. Kawata N, Kakushima N, Tanaka M, et al. Percutaneous endoscopic gastrostomy for decompression of malignant bowel obstruction. Digestive Endoscopy. 2014; 26(2):208-213.

12. Ritchie J, Spencer L (1994) Qualitative data analysis for applied policy research. In: Bryman A, Burgess RG, eds. Analyzing qualitative data. Routledge, London: 173-194.

13. Dixon-Woods, M. (2011) Using framework-based synthesis for conducting reviews of qualitative studies. BMC medicine 9,1, 39.

14. Gale, N.K., Heath, G., Cameron, E., Rashid, S. and Redwood, S. (2013) Using the framework method for the analysis of qualitative data in multi-disciplinary health research. BMC Medical Research Methodology 2013, 13:117.

15. Pope, C., Ziebland, S. And Mays, N. (2000) Qualitative research in health care: Analysing qualitative data. BMJ, 320, 114-116.

16. Ritchie J, Spencer L, O'Connor W (2003) Carrying out qualitative analysis. In: Ritchie J, Lewis J, eds. Qualitative research practice. A guide for social science students and researchers. Sage Publications, London: 219-262.

17. Ward D.J., Furber C., Tierney S., Swallow V. (2013) Using Framework Analysis in nursing research: a worked example. Journal of Advanced Nursing 69(11), 2423-2431. 10.1111/jan.12127. 